\title{
Núcleos de Acessibilidade nas Universidades: reflexões a partir de uma experiência institucional
}

\author{
Francisco Ricardo Lins Vieira de Melo \\ Universidade Federal do Rio Grande do Norte - Natal - RN - Brasil \\ Eliana Rodrigues Araújo \\ Universidade Federal do Rio Grande do Norte - Natal - RN - Brasil
}

\begin{abstract}
Resumo
A atual política educacional no contexto brasileiro preconiza a garantia de um sistema educacional inclusivo em todos os níveis de ensino. Dados do Censo da Educação Superior de 2013 registram um aumento de 575.4\%, entre os anos de 2003 e 2013 , no número de estudantes com deficiência nas instituições de ensino superior. Esse crescimento decorre de um conjunto de medidas inseridas na legislação brasileira para garantir o acesso e as condições de atendimento adequadas às pessoas com deficiência nesse nível de ensino. O presente estudo descritivoanalítico de base documental utiliza normativas institucionais como fonte de dados, no período de 2011 a 2015, objetivando descrever a atuação do Núcleo de Acessibilidade na Universidade Federal do Rio Grande do Norte/UFRN, e discorrer algumas reflexões acerca dessa experiência. O estudo busca contribuir com as discussões sobre a inclusão no ensino superior brasileiro, bem como o aprimoramento dos serviços de apoio oferecido neste contexto.
\end{abstract}

Palavras-chave: Ensino superior; educação especial; serviço de apoio.

\section{Accessibility Centers in Universities: reflections from an institutional experience}

\begin{abstract}
The current educational policy in the Brazilian context advocates the guarantee of an inclusive educational system at all levels of education. Data from the Higher Education Census of 2013 show an increase of $575.4 \%$ between 2003 and 2013 in the number of students with disabilities in higher education institutions. This growth stems from a set of measures inserted in the Brazilian legislation to guarantee access and adequate conditions of care for people with disabilities at this level of education. This descriptive-analytical, documentary-based study uses institutional norms as a source of data, from 2011 to 2015 , with the purpose of describing the work of the Accessibility Center at the Federal University of Rio Grande do Norte / UFRN, and discussing some of this experience. The study seeks to contribute to the discussions about inclusion in Brazilian higher education, as well as the improvement of the support services offered in this context.
\end{abstract}

Keywords: Higher education; special education; support service.

\section{Núcleos de accesibilidad en las universidades: reflexiones a partir de una experiencia institucional}

\begin{abstract}
Resumen
La actual política educacional en el contexto brasileño preconiza la garantía de un sistema educacional inclusivo en todos los niveles de enseñanza. Datos del Censo de la Educación Superior de 2013 registran un aumento del 575.4\%, entre los años de 2003 y 2013, en el número de estudiantes con deficiencia en las instituciones de enseñanza superior. Este crecimiento viene de un conjunto de medidas inseridas en la legislación brasileña para garantizar el acceso y las condiciones de atención adecuadas a las personas con deficiencia en este nivel de enseñanza. El presente estudio descriptivo-analítico de base documental utiliza normativas institucionales como fuente de datos, en el período de 2011 a 2015 , con el objetivo de describir la actuación del Núcleo de Accesibilidad en la Universidad Federal de Rio Grande do Norte/UFRN, y discurrir algunas reflexiones acerca de esa experiencia. El estudio busca contribuir con las discusiones sobre la inclusión en la enseñanza superior brasileña, así como el perfeccionamiento de los servicios de apoyo ofrecido en este contexto.
\end{abstract}

Palabras clave: Enseñanza superior; educación especial; servicio de apoyo. 


\section{Introdução}

O ingresso de estudantes com Necessidades Educacionais Especiais - NEE, especificamente daqueles com deficiência, nas universidades não é mais uma utopia, inclusive na Universidade Federal do Rio Grande do Norte - UFRN. Indicadores da educação das pessoas com deficiência no Brasil apontam que o crescimento de matrículas no ensino superior cresceu, em dez anos, aproximadamente 575,4\% passando de 5.078 matrículas em 2003 para 29.221 matrículas em 2013 (Brasil, 2013).

Esse crescimento decorre de um conjunto de medidas inseridas na legislação brasileira para garantir o acesso e as condições de atendimento adequadas às pessoas com deficiência no Ensino superior, destacando-se, entre outras, as exigências da Lei de Diretrizes e Bases da Educação Nacional (LDB), Lei nº 9.394 (1996), Portaria nº 3.284 (2003), a Política Nacional de Educação Especial na Perspectiva da Educação Inclusiva (Brasil, 2008a), Decreto nº 7.611 (2011) e a Lei $n^{\circ} 13.146$ (2015).

Neste contexto, o Ministério da Educação - MEC, por meio da Secretaria de Educação Superior/SESU e da Secretaria de Educação Continuada, Alfabetização, Diversidade e Inclusão/SECADI, criou em 2005 o Programa Incluir, como uma das ações afirmativas no âmbito das Instituições Federais de Ensino Superior (IFES), com o objetivo de fomentar a criação e a consolidação de núcleos de acessibilidade, sendo este entendido como

\footnotetext{
...a constituição de espaço físico, com profissional responsável pela organização das ações, articulação entre os diferentes órgãos e departamentos da universidade para a implementação da política de acessibilidade e efetivação das relações de ensino, pesquisa e extensão na área. Os Núcleos deverão atuar na implementação da acessibilidade às pessoas com deficiência em todos os espaços, ambientes, materiais, ações e processos desenvolvidos na instituição. (Brasil, 2008b, p.39).
}

De fato, a criação do Programa Incluir foi essencial para a condução da política e estruturação das ações voltadas aos estudantes com NEE na UFRN (Melo, 2015).

Ressalta-se também o Programa de Apoio a Planos e Reestruturação e Expansão das Universidades Federais/ REUNI pelo Decreto $n^{\circ} 6.096 / 2007$, cujo advento demarca a ampliação do ingresso de estudantes oriundos de camadas sociais desfavorecidas, dentre as quais se destacam as pessoas com NEE, particularmente aquelas com deficiência (Decreto 6.096, 2007).

A adoção de políticas afirmativas, no âmbito da democratização do ensino superior pretendida pelo REUNI, teve como desdobramento a necessidade de políticas que oferecessem sustentação a essa proposta e proporcionasse condições de permanência do estudante em condições de vulnerabilidade no ensino superior. Essa nova realidade demanda o repensar da política institucional com vistas a implementar mudanças efetivas que garantam a esses estudantes os recursos e os meios necessários para participarem das atividades de ensino, pesquisa e extensão, com o máximo de autonomia e sucesso ao longo de sua trajetória acadêmica. Tal constatação fomentou a criação do Programa Nacional de Assistência Estudantil - PNAES (Decreto 7.234, 2010).

Apesar das políticas afirmativas estarem implementadas em grande parte das IFES, ainda são escassos os estudos analisando a situação dos estudantes com deficiência diante dessas políticas (Duarte, Rafael, Filgueiras, Neves, \& Ferreira, 2013).

Diante desse cenário a UFRN dispõe de uma política de inclusão definida no seu Plano de Desenvolvimento Institucional - PDI, que leva em consideração um dos princípios políticos da gestão que está embasado no respeito à diversidade, "como valor geral para garantir o direito de identidade - pessoal, de grupos e institucional - atendendo às diferenças, sem discriminação, de modo a contemplar as características próprias de cada um com vistas a permitir o desenvolvimento pleno de suas potencialidades" (Universidade Federal do Rio Grande do Norte [UFRN] 2012a, p.17).

Esta por sua vez, tem como um dos objetivos institucionais,

induzir ações favoráveis à cultura democrática e ética, ao respeito à diversidade e à pluralidade, buscando uma abordagem institucional multi e interdisciplinar, objetivando ampla participação nas decisões, transparência e lisura dos atos administrativos; eliminação de toda e qualquer forma de discriminação a pessoas, grupos sociais e instâncias institucionais; fortalecendo o diálogo, o exercício da crítica e a convivência com os contrários (UFRN, 2012a, p.36).

Assim, o presente trabalho tem como objetivo descrever e discutir algumas das ações desenvolvidas pela UFRN no âmbito de sua política de inclusão voltadas para estudantes com NEE, na gestão 2011-2015, bem como suscitar algumas reflexões acerca do trabalho que a universidade vem desenvolvendo para esse coletivo com vistas a contribuir com a discussão para o aprimoramento dos núcleos de acessibilidade nas universidades.

\section{A institucionalização do Núcleo de Acessibilidade/ CAENE na UFRN}

Visando dar resposta aos dispositivos legais à luz do paradigma da educação inclusiva e às suas diretrizes institucionais, a UFRN criou no ano de 2010 o Núcleo de Acessibilidade denominado Comissão Permanente de Apoio ao Estudante com Necessidade Educacional Especial (CAENE), através da Portaria $n^{\circ}$ 203/2010, vinculada à reitoria, respaldado pela Resolução n¹93/2010 - CONSEPE, que dispõe sobre $o$ atendimento educacional destinado a esse alunado (UFRN, 2010a, 2010b). A CAENE tem como objetivos principais intervir e acompanhar, na perspectiva interdisciplinar, a trajetória do estudante com NEE, mediando o suporte educacional para o desenvolvimento de seu proces- 
so de ensino-aprendizagem. Além disso, orienta a política de inclusão do estudante com NEE visando contribuir para a tomada de decisões e fortalecimento dessa política em nível institucional. Sua missão é propor ações para eliminação de barreiras arquitetônicas, atitudinais, de comunicação e pedagógicas, visando contribuir para o acesso, permanência e conclusão de curso com sucesso do público alvo a que se destina, a saber: estudantes com Deficiências (Física, Auditiva, Visual, Intelectual ou Múltipla), Altas Habilidades/ Superdotação e Transtornos do Espectro Autista, bem como os estudantes com transtornos funcionais específicos, dentre os quais se incluem os estudantes com Transtornos Específicos de Aprendizagem, aqueles com Transtorno do Déficit de Atenção e Hiperatividade - TDH/A e com Dificuldades Secundárias de Aprendizagem (Transtornos Mentais ou Doenças Crônicas).

No que se refere às medidas que possam promover a acessibilidade curricular durante a trajetória acadêmica, a CAENE tem proposto a implementação de procedimentos e recursos de ensino-aprendizagem e avaliação apropriados a especificidade da NEE, tais como: elaboração de materiais pedagógicos de leitura e escrita em Braille, textos impressos em fonte ampliada; ledores; disponibilização de recursos tecnológicos; tradutor intérprete de Libras; flexibilização na correção das provas para alunos surdos; comunicação alternativa; adequação de mobiliário, equipamentos e ambientes acessíveis.

\section{Método}

A presente pesquisa, de abordagem qualitativa, foi baseada num estudo descritivo-analítico de base documental, utilizando como fonte de dados normativas institucionais da UFRN, no período de 2011 a 2015, objetivando descrever a atuação do seu Núcleo de Acessibilidade a partir da legislação vigente sobre a inclusão da pessoa com deficiência no Ensino Superior.

\section{Procedimentos de Coleta e Análise dos Dados}

Os documentos que serviram de fonte de dados foram selecionados e analisados com base na importância que assumiram na efetivação da institucionalização da política de inclusão na UFRN e nas ações desenvolvidas pelo Núcleo de Acessibilidade, foco deste estudo, como: o Plano de Desenvolvimento Institucional (2010-2019), o Plano de Gestão (2011-2015), a Portaria $n^{\circ}$ 203/2010, a Resolução n¹93/2010 - CONSEPE, a Resolução n¹71/2013 - CONSEPE, a Resolução n054/2014 - CONSEPE, a Resolução n¹63/2014 - CONSEPE e a Portaria n 001/2012 - PROGRAD, além de outros documentos que subsidiam a política de inclusão para às pessoas com deficiência no Ensino Superior brasileiro (UFRN, 2010a, 2010b, 2012b, 2013, 2014a, 2014b). Os resultados apresentados por meio das ações são sustentados e discutidos com base nos documentos analisados.

\section{Ações desenvolvidas pelo Núcleo de Acessibilidade/CAENE}

Mediante a impossibilidade de fazermos uma análise mais ampla de todas as ações empreendidas no trabalho realizado pela CAENE no período da gestão de 2011 a 2015 , optamos por discutir quatro aspectos que julgamos relevantes para esse recorte: a) Atendimento aos estudantes com NEE; b) Apoio social; c) Formação continuada e d) Infraestrutura.

\section{a) Atendimento aos estudantes com NEE}

Com a implantação da CAENE, os indicadores apontam para um crescimento do número de alunos com NEE ingressantes na UFRN, particularmente nos cursos de graduação presenciais. Do período de 2011 a 2015 a UFRN contou com o ingresso de 215 estudantes com NEE. Ressalta-se que mesmo diante do crescimento gradativo do ingresso de alunos com NEE na graduação nesse período, esse número ainda é inexpressivo quando comparado ao número total de alunos matriculados, como pode ser observado no Quadro 1, abaixo.

Os dados da UFRN refletem a constatação do que os números vêm sinalizando em termos de matrículas de estudantes com deficiência no Ensino Superior brasileiro. De acordo com o Censo da Educação Superior MEC/INEP, em 2004, foram registradas 5.078 matrículas de estudantes

Quadro 1. Número de estudantes ingressantes na UFRN no período de 2011-2015.

\begin{tabular}{|c|c|c|c|c|c|c|c|c|c|c|}
\hline \multirow{2}{*}{ Graduação } & \multicolumn{2}{|c|}{2011} & \multicolumn{2}{|c|}{2012} & \multicolumn{2}{|c|}{2013} & \multicolumn{2}{|c|}{2014} & \multicolumn{2}{|c|}{2015} \\
\hline & Total & NEE* & Total & NEE$^{*}$ & Total & NEE* & Total & NEE $^{*}$ & Total & $\mathrm{NEE}^{*}$ \\
\hline $\begin{array}{c}\text { Total de } \\
\text { estudantes }\end{array}$ & 7.890 & 41 & 10.015 & 45 & 8.509 & 55 & 9.042 & 43 & 7.432 & 31 \\
\hline
\end{tabular}

Fonte: Universidade Federal do Rio Grande Do Norte (2015).

*NEE - Estudantes que solicitaram apoio a CAENE por ano de ingresso. 
com deficiência e, em 2014, foram 33.475; um crescimento de $559 \%$ do total de matrículas.

No entanto, mesmo diante dos avanços decorrentes da política educacional ainda estamos longe de uma participação efetiva desse público no Ensino Superior. Se tomarmos a título de exemplo o total de matrículas de estudantes no ano de 2014, 7.828.013, a participação desse alunado com deficiência no referido ano foi de apenas 0,42\% (33.475). Além disso, essas matrículas predominam nas instituições de Ensino Superior privadas como resultado notadamente do Programa Universidade Para Todos - PROUNI, instituído pela Lei $n^{\circ} 11.096$ (2005). Para Melo e Martins (2016, p. 265), o acesso desse público às universidades privadas tem sido observado com ressalva, "alegando-se, entre outros aspectos, que as formas de acesso, as facilidades de ingresso e a qualidade da formação recebida nessas instituições poderão repercutir-se, de forma negativa, na sua inserção no mercado de trabalho". Portanto, a democratização do acesso ao Ensino Superior público em nosso país ainda é uma utopia. Com a implementação da Lei n. 13.409 (2016), que altera a Lei $n^{\circ}$. 12.711 (2012), para dispor sobre a reserva de vagas para pessoas com deficiência nos cursos técnico de nível médio e superior das instituições federais de ensino, espera-se que essa realidade venha alterar-se em relação ao acesso dessa população ao Ensino Superior contribuindo para a democratização do acesso ao conhecimento.

No que diz respeito ao fluxo de atendimento, o estudante com NEE ou o docente busca a coordenação de seu curso para que essa possa solicitar apoio via Sistema Integrado de Gestão de Atividades Acadêmicas - SIGAA, à CAENE. Essa etapa é de fundamental importância para que a gestão da unidade acadêmica tome conhecimento de sua presença. Uma vez recebida a solicitação de apoio, a CAENE convida o estudante para as entrevistas iniciais a serem realizadas por assistente social, pedagoga e psicóloga e, dependendo do caso, também é realizada entrevista com pais/responsáveis. Nessa etapa, são investigados os históricos clínico, acadêmico e psicossocial do estudante, bem como a presença de NEE que possam subjazer à solicitação de apoio. Dependendo da triagem inicial, o estudante pode ser encaminhado para outros profissionais participarem do processo avaliativo e de intervenção.

De posse de tais informações, a equipe realiza reuniões interdisciplinares para a discussão dos casos a fim de discutir as estratégias de atendimento educacional e elaborar um parecer técnico. O parecer é apresentado ao estudante para apreciação e validação e, em seguida, parte do documento (orientações e estratégias educacionais) é encaminhada para a coordenação e o corpo docente em atividade com o estudante. Por sua vez, ele passa a ser acompanhado semestralmente ou segundo demandas espontâneas que venha a apresentar ao longo do semestre letivo.

No período de 2011 a 2015, considerando o público alvo da educação especial na política vigente (Brasil, 2008a), predominam, no contexto da CAENE, os estudantes com deficiência e, dentre estas, a deficiência visual, seguida da deficiência física. No entanto, constata-se um número expressivo de estudantes com outras NEE (Medeiros, Salgado-Azoni, \& Melo, 2016; Santos \& Melo, 2016). Quanto aos cursos de graduação, há o predomínio na área das Ciências Humanas, assim como de estudantes matriculados no campus central.

Outros desdobramentos importantes para a política de inclusão na UFRN, no período da gestão analisada, dizem respeito à publicação da Resolução No. 171/2013 CONSEPE, que aprova o Regulamento dos Cursos Regulares de Graduação, destacando normas relativas ao ensino de graduação de estudantes com NEE e da Resolução No 163/2014 - CONSEPE, que dispõe sobre a concessão de "Bolsa Acessibilidade" para Estudantes com Deficiência. Tais iniciativas têm contribuído para garantir os direitos e a igualdade de oportunidades desse público na universidade (UFRN, 2013, 2014b).

\section{b) Apoio social}

Sendo a universidade um espaço de construção de conhecimento e cidadania, torna-se imprescindível que ela esteja igualmente comprometida com a realidade social do discente. Desse modo, deve propiciar condições objetivas de permanência na Educação Superior, prevenindo causas da retenção e/ou evasão a partir das situações decorrentes de dificuldades socioeconômicas, aliada a outras formas resultantes das diferentes expressões da questão social, que por sua vez incidem de forma particular sobre o cotidiano da pessoa com deficiência e/ou NEE.

Sendo assim, o Serviço Social consiste em identificar os determinantes sociais, políticos, econômicos e culturais que interferem no sistema educacional e consequentemente na vida do aluno e propor alternativas de enfrentamento de forma a cooperar com a efetivação da educação como um direito para a conquista da cidadania. Então, pensar a dimensão pedagógica e educativa do Serviço Social é "remeter-se a um trabalho desenvolvido pelos profissionais na perspectiva de desmistificar e desvelar a realidade produtora e reprodutora de desigualdades, visando à autonomia, à participação e à emancipação dos indivíduos sociais" (Piana, 2009, p.185).

Neste sentido, as ações desenvolvidas pelo Serviço Social na CAENE ocorrem inicialmente por meio da avaliação social junto ao discente com NEE. Após constatar sua condição social, ele será encaminhado à Pró-Reitoria de Assuntos Estudantis - PROAE - para que possam pleitear as bolsas de Assistência Estudantil. Desse modo, no período de 2011 a 2015, houve um aumento significativo de bolsas concedidas aos alunos com NEE com o objetivo de garantir sua permanência durante a trajetória acadêmica na instituição (Quadro 2).

De acordo com o Quadro 2, percebe-se o aumento gradativo de bolsas concedidas pela PROAE a estudantes com NEE, priorizando na política de ação estudantil o que estabelece o Art. 3 do PNAES(Decreto $n^{0}$ 7.234, 2010). 
Quadro 2. Distribuição de bolsas estudantis para alunos com NEE no período de 2011-2015.

\begin{tabular}{llllll}
\hline \multicolumn{1}{c}{ TIPO DE BOLSA CONCEDIDA } & $\mathbf{2 0 1 1}$ & $\mathbf{2 0 1 2}$ & $\mathbf{2 0 1 3}$ & $\mathbf{2 0 1 4}$ & $\mathbf{2 0 1 5}$ \\
\hline Alimentação & 5 & 4 & 9 & 15 & 15 \\
\hline Residência & 1 & 3 & 6 & 12 & 12 \\
\hline Auxílio Transporte & 1 & 0 & 0 & 2 & 2 \\
\hline Bolsa Trabalho & 0 & 3 & 3 & 4 & 4 \\
\hline Bolsa Acessibilidade & 0 & 0 & 0 & 17 & 17 \\
\hline Bolsa Extensão & 0 & 0 & 0 & 4 & 4 \\
\hline Introdução à docência PIBID & 0 & 0 & 0 & 4 & 4 \\
\hline Iniciação Cientifica & 0 & 0 & 0 & 2 & 2 \\
\hline TOTAL & 7 & 10 & 18 & 60 & 60 \\
\hline
\end{tabular}

Fonte: UNIVERSIDADE FEDERAL DO RIO GRANDE DO NORTE, 2015.

Vale ressaltar que a Bolsa Acessibilidade, implementada durante o semestre de 2014.2, foi sem dúvida um dos grandes avanços obtidos, uma vez que o aluno com NEE pode permanecer com a referida bolsa durante todo seu processo formativo (Ferreira, 2016), desde que continue atendendo aos critérios estabelecidos na Resolução №. 163/2014 - CONSEPE, quais sejam, apresentar deficiência aliada à situação de vulnerabilidade social. Além disso, a bolsa citada possibilita que esses discentes obtenham o custeio de suas despesas com o deslocamento, bem como a aquisição de instrumentos pessoais e de apoio aos estudos (UFRN, 2014b).

\section{c) Formação continuada}

A presença de estudantes com NEE na universidade tem impactado principalmente nas relações de ensino no contexto de sala de aula. Estar diante de um estudante que demanda recursos e técnicas diferenciadas de ensino suscita o redirecionamento do olhar para a formação e atuação dos docentes universitários, no tocante ao pensar e agir do professor no ato de planejar, ensinar, aprender e avaliar.

Tal situação leva a maioria dos professores a ficar sem norte por não ter um embasamento teórico-prático a este respeito. Essa tem sido uma queixa frequente dos docentes trazidas durante as reuniões de orientação realizadas pela equipe de profissionais da CAENE.

A capacitação dos docentes para lidar com o aluno com NEE consiste num dos eixos fundamentais para a garantia de um ensino de qualidade, uma vez que a maioria não teve, em sua formação acadêmica, disciplinas suficientes abordando questões relacionadas ao atendimento de alunos com NEE que os preparassem para lidar em sala de aula com esse alunado. $O$ mesmo entendimento se aplica à capacitação dos servidores técnicos para lidar diretamente com o atendimento das pessoas com NEE, especificamente aquelas com deficiência.

A PROGRAD, entendendo a importância desse processo formativo para docentes, criou a Portaria $n^{\circ}$ 001/2012-PROGRAD (UFRN, 2012b) a qual institui uma comissão para elaborar uma proposta de formação continuada em educação para pessoas com NEE, a ser efetivada por meio do Programa de Atualização Pedagógica - PAP, assim como, a Pró-reitoria de Gestão de Pessoas - PROGESP, através da Divisão de Treinamento de Recursos Humanos, visando promoverem capacitações para docentes e técnicos. Neste sentido, a CAENE vem atuando em parceira com estas Pró-Reitorias, participando ativamente das ações formativas na temática da Inclusão e acessibilidade no Ensino Superior.

É preciso o entendimento de que a inclusão social é um paradigma que exige de toda a sociedade mudanças de atitudes e de conceitos em relação às pessoas com deficiência, e a universidade enquanto espaço de produção e socialização de conhecimentos pode e deve ser indutora dessa transformação, a começar pela derrubada de mitos e preconceitos acerca dessas pessoas construídas ao longo da história da humanidade. Sendo assim, levar informações científicas, corretas e coerentes sobre as pessoas com deficiência é fundamental para uma nova postura e desenvolvimento de uma cultura de respeito à diversidade. Nessa perspectiva, a CAENE também tem investido na produção de livros destinados aos docentes (Melo, 2013; Oliveira ; Santos \& Silva, 2014).

\section{Infraestrutura}

A infraestrutura com acessibilidade é um dos indicadores imprescindíveis para a participação efetiva e garantia da igualdade de oportunidades. Nesse sentido, a UFRN, em 
atendimento a legislação vigente (Decreto $\left.n^{\circ} 5.296,2004\right)$, tem assegurado em seu planejamento institucional recursos financeiros que respondam às demandas das pessoas com deficiência por meio de medidas que garantam acessibilidade aos serviços e instalações. Dentre as ações implementadas para infraestrutura, citam-se:

\section{- Setores/Serviços/Tecnologias de Apoio}

Criação do Laboratório de Acessibilidade na Biblioteca Central Zila Mamede (BCZM), do Setor de Acessibilidade na Secretaria de Educação à Distância (SEDIS) e o Setor de Musicografia Braille e Apoio a Inclusão (SEMBRAIN), na Escola de Música.

Para o desenvolvimento das ações nestes setores, eles estão equipados com recursos de tecnologia assistiva e com uma equipe de profissionais e bolsistas de apoio técnico qualificada para assegurar a produção e acesso de materiais acadêmicos em diferentes formatos acessíveis, destacando-se o Repositório de Informação Acessível institucionalizado pela Resolução n 054/2014 - CONSEPE. (Furtado, 2016; Melo \& cols., 2014, UFRN, 2014a).

Ressalta-se, também, o serviço de tradutores-intérpretes de Libras e o serviço de capacitação para utilização e empréstimo de tecnologia assistiva. O deferimento da solicitação leva em conta o tipo de NEE e a condição social e econômica do estudante.

Quanto à formação da equipe para atuação nos referidos setores, inclusive na CAENE, tem sido fundamental o papel da PROGESP, PROAE e Pró-Reitoria de Planejamento (PROPLAN), na nomeação, contratação e remanejamento de profissionais com vistas a garantir o acompanhamento qualificado dos estudantes com deficiência ou outras NEE. A equipe da CAENE atualmente está constituída por pedagogas, assistentes sociais, psicólogas, revisor Braille, técnicos administrativos, design gráfica, bibliotecárias, tradutores intérpretes de Libras, além discentes na função de tutores e bolsistas de apoio técnico.

\section{Acessibilidade física}

A CAENE tem buscado somar esforços junto à Superintendência de Infraestrutura - SIN, no sentido de contribuir com as questões em torno da acessibilidade física. Dentro deste foco de atenção, constata-se ao longo do período analisado, um conjunto de ações desenvolvidas e em processo para tornar os espaços da UFRN acessíveis, dentre as quais se destacam: Diagnóstico das condições de acessibilidade física; Elaboração e distribuição de um Manual intitulado "Acessibilidade na UFRN: guia de orientações básicas" (Souza \& Melo, 2012); Capacitação de gestores e docentes sobre acessibilidade física;Campanha de Acessibilidade "Eu posso! você deixa?"; I Fórum Permanente de Acessibilidade "o direito de ir e vir"; Concurso fotográfico "Acessibilidade e Respeito"; Consultoria externa a projetos de acessibilidade; Construção de rotas acessíveis e rampas e criação de Co- missão para elaboração do Plano de Mobilidade e Acessibilidade do Campus Central (Melo; Saraiva \& Souza,2013).

\section{Reflexões de uma prática em construção}

Esse novo paradigma educacional cujo princípio é a inclusão de todos no sistema de ensino com base no respeito às diferenças, exige, além de materiais, currículos adaptados, estratégias de ensino inclusivas e acessibilidade em todas as dimensões (arquitetônica, instrumental e pedagógica), profundas mudanças nas concepções de ensino e aprendizagem, valorização da diversidade, discussões e exercício educativo concernente à quebras de barreiras atitudinais, para que as transformações necessárias realmente aconteçam (Ferrari \& Sekkel, 2007).

Infelizmente, ainda há, por parte da sociedade como um todo, inclusive nas instituições de ensino, a concepção de deficiência associada à doença, no qual a pessoa com deficiência é focalizada a partir de suas limitações. Esta compreensão, advinda do modelo médico de deficiência, negligencia o rol de possibilidades e potencialidades que se apresenta a este segmento de alunado. Além disso, constata-se que, como consequência desta concepção equivocada por parte da comunidade universitária, associa-se a CAENE a um espaço voltado para tratamento clínico. Apesar do empenho na divulgação do papel e dos serviços didático-pedagógicos disponibilizados pela CAENE, é preciso uma maior clareza, por parte da comunidade universitária, acerca da finalidade que assume esse setor na UFRN, desvinculando-o da abordagem terapêutica, além de priorizar em sua agenda eventos de caráter educativos e sociais que provoquem mudanças conceituais e atitudinais diante das pessoas com NEE, principalmente daquelas com deficiência, com o propósito de construir uma cultura organizacional inclusiva.

Mesmo com a existência da CAENE e outros setores de apoio aos estudantes com NEE, a instituição ainda não conseguiu a adesão de todos os discentes no que tange à autodeclaração de condição que gera NEE, durante o ingresso no ato da matrícula, para que seja possível planejar ações e metas voltadas para prevenir o insucesso acadêmico e oferecer o suporte específico que necessitam. Dessa forma, é possível que os números que se apresentam não sejam representativos da realidade existente na UFRN, tendo em vista que muitos estudantes com NEE - principalmente aqueles com transtorno mental, transtornos do espectro autista, deficiência intelectual e com transtornos específicos da aprendizagem - se sentem constrangidos ou têm medo de expor suas deficiências ou NEEs e se negam a procurar apoio ou, quando o fazem, pedem sigilo no que diz respeito a não ter o nome nos registros do sistema da universidade. Nesses casos, por não existir documentação institucionalizada sobre sua condição, a CAENE não pode assegurar todos os seus direitos enquanto estudante com NEE. Em outros casos, a demanda só é notificada diante de indicações de colegas e/ou professores após ocorrências atípicas em sala de aula. 
A presença desses alunos em sala de aula pode criar situações constrangedoras e muitas vezes não há o conhecimento por parte da instituição (Ferrari \& Sekkel, 2007). Nesses casos, o desafio tem sido distinguir as ações que dizem respeito exclusivamente ao processo de ensino-aprendizagem através de estratégias educacionais específicas da situação de cada aluno. Porém, isso só é possível desde que esses alunos se autodeclarem e procurem os serviços da CAENE.

Nossa experiência confirma a afirmação de que a atitude e a forma de intervenção das equipes docentes no contexto inclusivo são necessariamente diferentes do ensino tradicionalmente conhecido e efetivado nas práticas docentes (Simão, Santos,\& Costa, 2002). Assim, o alvo crítico em um trabalho com alunos com NEE diz respeito ao suporte educacional, monitoramento e acompanhamento da trajetória desses em todo percurso acadêmico por meio de uma equipe interdisciplinar, o que ainda não é a realidade de muitos núcleos de acessibilidade nas universidades brasileiras.

Parte dos estudantes com NEE atendidos pela CAENE, além das dificuldades demandadas pela condição da NEE, apresenta situação de vulnerabilidade socioeconômica. Essa condição favorece a redução de suas possibilidades de sucesso resultando muitas vezes em comprometimento do desempenho acadêmico, retenção e/ou evasão. Nesse sentido, não basta apenas institucionalizar o Núcleo de Acessibilidade com a finalidade de eliminar as barreiras pedagógicas, arquitetônicas, de comunicação ou atitudinais se não forem dadas as condições objetivas para garantir a sua permanência com êxito, como preconizada pelo PNAES (Decreto $\left.n^{\circ} 7.234,2010\right)$. É preciso dentre as ações desenvolvidas pelo Núcleo de Acessibilidade em parceria com outras Pró-Reitorias, particularmente as relacionadas às questões acadêmicas, um olhar atento para assegurar a esses alunos todos os benefícios sociais garantidos por lei.

Apesar de a UFRN estar priorizando em sua política institucional a capacitação de docentes e técnicos sobre temas relacionados à inclusão, acessibilidade e NEE, essa não tem sido uma tarefa fácil. Infelizmente, a procura por essas capacitações tem sido em sua maioria pelos professores que estão tendo experiências com esses estudantes em sala de aula ou por interesses próprios. O mesmo se aplica aos técnicos; geralmente a procura por capacitação nessa área está relacionada ao convívio com pessoas com deficiência no ambiente de trabalho ou a situações em que o técnico está envolvido com atendimento ao público. Essa realidade indica que mesmo não havendo a adesão esperada nas capacitações, a presença da pessoa com deficiência na universidade tem provocado a comunidade acadêmica a buscar informações sobre esse coletivo.

Martins (2016), em uma pesquisa realizada na UFRN, constatou que mesmo com a oferta crescente de cursos e palestras voltadas à temática da inclusão, ainda é escassa a participação de docentes, apontando a desmotivação por parte destes em formações voltadas para o campo do ensino e o atendimento à diversidade diante do aluno com deficiência no Ensino Superior.

A infraestrutura não pode apenas ser vista sobre a perspectiva arquitetônica. Para além dos ambientes acessíveis, a infraestrutura envolve serviços e produtos disponibilizados às pessoas com deficiência. A UFRN tem ofertado a esse público diversos serviços graças à criação de setores que têm como objetivo comum levar o estudante com NEE ao êxito acadêmico e social. É preciso que todos os gestores, particularmente os diretores de centro e unidades, se impliquem nesse processo colocando na pauta de sua agenda o compromisso pela efetivação da política de inclusão definido no Plano de Desenvolvimento Institucional de modo a instituir as condições de acessibilidade necessárias ao centro ou unidade sob sua responsabilidade gestora.

Outro desafio posto é a contratação de profissionais para compor a equipe do Núcleo de Acessibilidade com a finalidade de garantir um atendimento educacional especializado, particularmente no que tange aos estudantes com Altas Habilidades, com Transtornos do Espectro Autista, com Surdocegueira e porque não citar, também, os transtornos específicos de aprendizagem? De fato, trabalhar com esse alunado implica em competências e habilidades profissionais que ainda não temos condições de reunir em um único espaço físico. Isto mostra o quanto é importante a articulação institucional para garantir vagas para determinados perfis profissionais, do trabalho em rede intra e extra institucional e da conscientização da responsabilidade de cada setor e de todos os atores da instituição para uma efetiva inclusão na universidade.

\section{Conclusão}

A criação da CAENE representa um marco na história da UFRN e delimita uma mudança precípua na política institucional voltada para os estudantes com NEE. Esses estudantes têm conseguido sair da invisibilidade e permanecer na instituição, tendo-se verificado melhorias em seu desenvolvimento acadêmico, as quais vêm formando importantes alicerces para a sua conclusão de curso com sucesso. Constata-se que a presença da CAENE tem sido um referencial importante de articulação dentro da instituição que tem fortalecido a política de inclusão e desenvolvido ações em prol da melhoria das condições de atendimento aos estudantes com NEE.

Embora seja um trabalho recente, destaca-se que, como resultado dessa atuação, os estudantes vêm buscando a efetivação dos seus direitos, e vêm ampliando a sua participação política, inserindo a temática da inclusão educacional na pauta do movimento estudantil da UFRN. Considera-se que o trabalho realizado pela CAENE tem impactado no que tange à minimização das barreiras enfrentadas pelos estudantes na instituição, notadamente aquelas de caráter didático-pedagógico e social. No entanto, observa-se que ainda são necessários avanços no que concerne à trans- 
posição das barreiras atitudinais que perpassam a trajetória acadêmica dos estudantes com NEE.

Contata-se que durante a gestão da UFRN no período de 2011 a 2015 houve um grande investimento institucional no que tange à política de inclusão voltada para os estudantes com NEE cujos desdobramentos foram mencionados ao longo deste texto. Mesmo diante dos avanços, a CAENE tem consciência de que estamos num processo constante de aprendizado interdisciplinar e que o diálogo e a troca de experiências com outras instituições têm sido um dos caminhos para juntos construirmos e consolidarmos práticas bem sucedidas para estudantes com NEE no ensino superior.

\section{Agradecimentos}

A todos os gestores e unidades acadêmicas, profissionais da CAENE e dos demais serviços de apoio e à comunidade acadêmica como um todo que tem contribuído para construção e fortalecimento da política de inclusão da UFRN.

\section{Referências}

Brasil. Ministério da Educação (2008a). Política Nacional de Educação Especial na Perspectiva da Educação Inclusiva. Brasília, DF. Recuperado: 25 mar. 2015. Disponível: http://portal.mec.gov.br/ arquivos/pdf/politicaeducespecial.pdf.

Brasil. Ministério da Educação (2008b). Secretaria de Educação Superior. Edital $n^{\circ}$ 4. Seleção de Propostas. Programa Incluir: acessibilidade na educação superior. Diário Oficial da União, Brasília, DF, n. 84, seção 3, p.39-40, 5 maio. Recuperado: 23 jan. 2018. Disponível: http://portal.mec.gov.br/index.php?option=com_ docman\&view=download\&alias $=816$-incluir-propostaspdf\&category_slug=documentos-pdf\&ltemid=30192

Brasil. Ministério da Educação (2013). Censo da Educação Superior: 2013. Brasília, DF.

Decreto $n^{\circ} 5.296$ de 2 de Dezembro de 2004 (2004, 2 de dezembro). Regulamenta as Leis nos 10.048 , de 8 de novembro de 2000, que dá prioridade de atendimento às pessoas que especifica, e 10.098, de 19 de dezembro de 2000, que estabelece normas gerais e critérios básicos para a promoção da acessibilidade das pessoas portadoras de deficiência ou com mobilidade reduzida, e dá outras providências. Brasília, DF. Recuperado: 16 jan. 2014. Disponível: http://www. planalto.gov.br/ccivil_03/_ato2004-006/2004/decreto/d5296.htm.

Decreto $n^{\circ}$ 6.096, de 24 de abril de 2007 (2007, 24 de abril). Institui o Programa de Apoio a Planos de Reestruturação e Expansão das Universidades Federais - REUNI. Brasília, DF. Recuperado: 26 jan. 2017. Disponível: http://www.planalto.gov.br/ccivil_03/_ ato2007-010/2007/decreto/d6096.htm.

Decreto $n^{\circ}$ 7.234, de 19 de julho de 2010 (2010, 19 de julho). Dispõe sobre o Programa Nacional de Assistência Estudantil - PNAES.
Brasília, DF. Recuperado: 26 jan. 2017. Disponível: http://www. planalto.gov.br/ccivil_03/_Ato2007-2010/2010/Decreto/D7234.htm.

Decreto $n^{\circ} 7.611$, de 17 de novembro de 2011 (2011, 17 de novembro). Dispõe sobre a educação especial, o atendimento educacional especializado e dá outras providências. Brasília, DF. Recuperado: 26 janeiro. 2017, de http://www.planalto.gov.br/ccivil_03/_Ato2011014/2011/Decreto/D7611.htm

Duarte, E.R.; Rafael, C.B.S.; Filgueiras, J.F.; Neves, C.M.; Ferreira, M.E.C. (2013). Estudo de Caso Sobre a Inclusão de Alunos com Deficiência no Ensino Superior. Revista Brasileira de Educação Especial, 19 (2), 289-300.

Ferrari, M.A.L.D.; Sekkel, C. (2007). Educação Inclusiva no Ensino Superior: um novo desafio. Psicologia Ciência e Profissão, 27(4), 636-647.

Ferreira, E.L.L.S. (2016). A política de inclusão de estudantes cegos na educação superior na UFRN: do acesso à permanência. Dissertação de Mestrado, Universidade Federal do Rio Grande do Norte, Natal, RN, Brasil.

Furtado, M.M.D.F. (2016). Usabilidade e acessibilidade no Repositório de Informação Acessível da UFRN: avaliação ergonômica de interfaces Web. Dissertação de Mestrado, Universidade Federal do Rio Grande do Norte, Natal, RN, Brasil.

Lei $n^{\circ}$ 9.394/96, de 20 de dezembro de 1996 (1996, 20 de dezembro). Diretrizes e bases da educação nacional. Diário Oficial da União, Brasília, DF, 23 dez. 1996. Seção 1, p. 1.

Lei $n^{\circ}$ 13.146, de 6 de Julho de 2015 (2015, 6 de julho). Institui a Lei Brasileira de Inclusão da Pessoa com Deficiência (Estatuto da Pessoa com Deficiência). Brasília, DF, 2015. Recuperado: 26 jan. 2017. Disponível: http://www.planalto.gov.br/ccivil_03/_ato20152018/2015/Lei/L13146.htm.

Lei $n^{\circ}$ 13.409, de 28 de dezembro de 2016 (2016, 28 de dezembro). Altera a lei $n^{\circ} 12.711$, de 29 de agosto de 2012, para dispor sobre a reserva de vagas para pessoas com deficiência nos cursos técnico de nível médio e superior das instituições federais de ensino. Brasília, DF, 2016. Recuperado: 23 jan. 2018. Disponível: http:// www.planalto.gov.br/ccivil_03/_ato2015-2018/2016/lei/L13409.htm

Lei $n^{\circ}$ 12.711, de 29 de agosto de 2012 (2012, 29 de agosto). Dispõe sobre o ingresso nas universidades federais e nas instituições federais de ensino técnico de nível médio e dá outras providências. Brasília, DF, 2012. Recuperado: 23 jan. 2018. Disponível: http:// www.planalto.gov.br/ccivil_03/_ato2011-2014/2012/lei//12711.htm

Martins, L.M.S.M. (2016). Práticas e formação docente na UFRN com vistas à inclusão de estudantes cegos. Dissertação de Mestrado, Universidade Federal do Rio Grande do Norte, Natal, RN.

Medeiros, E.C.M.R.; Salgado-Azoni, C.A.; Melo, F.R.L.V. (2016). A vida escolar de um adulto com dislexia: desafios na universidade. 
Um estudo de caso na Universidade Federal do Rio Grande do Norte-Brasil. In: Marques, J.F.; Martins, M.H. (Orgs.), Univers(al) idade: Estudantes "não tradicionais" no Ensino Superior: transições, obstáculos e conquistas (pp. 66-75).Faro-Portugal: Universidade do Algarve.

Melo, F.R.L.V. (Org.). (2013). Inclusão no Ensino Superior: docência e necessidades educacionais especiais. Natal: EDUFRN.

Melo, F.R.L.V. de; Saraiva, L.L.O.; Souza, N.G. de. (2013). A Comissão Permanente de Apoio a Estudantes com Necessidades Educacionais Especiais e os Desdobramentos da Acessibilidade Física na UFRN. Anais do $3^{\circ}$ Seminário Internacional Inclusão em Educação: Universidade e participação. Rio de Janeiro, RJ: Editora Universidade Federal do Rio de Janeiro.

Melo, F.R.L.V. (2015). O Programa Incluir na Universidade Federal do Rio Grande do Norte: conquistas e desdobramentos institucionais. In: Mendes, M.E.; Almeida, M.A. (Orgs.), Educação Especial Inclusiva: legados históricos e perspectivas futuras (pp. 273-285). São Carlos: Marquezine \& Manzini; ABPEE.

Melo, F.R.L.V.; Furtado, M.F.D.F.; Ribeiro, E.S.K.; Melo, E.S.F.; Araújo, A.B.; Trindade, S.S. (2014). Experiências e Iniciativas em Acessibilidade e Inclusão na UFRN: o Laboratório de Acessibilidade da Biblioteca Central Zila Mamede. Revista Gestão \& Conexões, 3, 43-67. Recuperado: 3 out. 2014.Disponível: www. periodicos.ufes.br/ppgadm/article/download/5052/5579.

Melo, F.R.L.V.; Martins, M.H. (2016). Legislação para estudantes com deficiência no ensino superior no Brasil e em Portugal: algumas reflexões. Acta Scientiarum. Education, 38(3), 259-269.

Oliveira, L.N.S.; Santos, P.R.A.; Silva, R.S. (2014). Conversando com o Professor sobre: Surdez e deficiência auditiva. In: Melo. F.R.L.V. (Org.) Natal: EDUFRN.

Piana, M.C. (2009). Serviço Social e Educação: olhares que se entrecruzam. Serviço Social \& Realidade, 18 (2), 182-206.

Portaria $n^{\circ} 3.284$, de 7 de novembro de 2003. (2003). Dispõe sobre requisitos de acessibilidade de pessoas portadoras de deficiências, para instruir os processos de autorização e de reconhecimento de cursos, e de credenciamento de instituições. Brasília, DF. Recuperado: 26 jan. 2017. Disponível: http://portal.mec.gov.br/ seesp/arquivos/pdf/port3284.pdf.

Santos, C.P.; Melo, F.R.L.V. (2016). Psicologia escolar e práticas de inclusão do ensino superior: a experiência da CAENE-UFRN. Anais do $7^{\circ}$ Congresso Brasileiro de Educação Especial. São Carlos, SP: CBEE.

Simão, V.J.; Santos, S.M.; Costa, A. (2002). Ensino Superior: uma visão para a próxima década. Lisboa: Gradiva.
Souza, N.G.; Melo, F.R.L.V. (2012). Acessibilidade na UFRN: guia de orientações básicas, 1. Natal: EDUFRN.

Universidade Federal do Rio Grande do Norte [UFRN] (2010a). Portaria $N^{\circ}$ 203/10-R, de 15 de março de 2010. Institui comissão permanente denominada Núcleo de Apoio a Estudantes com Necessidades Educacionais Especiais, vinculada ao Gabinete do Reitor da Universidade Federal do Rio Grande do Norte. Natal: UFRN.

Universidade Federal do Rio Grande do Norte [UFRN] (2010b). Resolução 193/2010-CONSEPE, de 21 de setembro de 2010. Dispõe sobre o atendimento educacional a estudantes com necessidades educacionais especiais na Universidade Federal do Rio Grande do Norte. Natal: UFRN.

Universidade Federal do Rio Grande do Norte [UFRN] (2012a). Novas conquistas: plano de gestão 2011 - 2015. Natal: UFRN.

Universidade Federal do Rio Grande do Norte [UFRN] (2012b). Portaria n. 001/2012-PROGRAD, de 12 de março de 2012. Natal: UFRN.

Universidade Federal do Rio Grande do Norte [UFRN] (2013). Resolução n. 171/2013-CONSEPE, de 5 de novembro de 2013. Aprova o Regulamento dos Cursos Regulares de Graduação da Universidade Federal do Rio Grande do Norte. Natal: UFRN.

Universidade Federal do Rio Grande do Norte [UFRN] (2014a). Resolução n. 054/2014-CONSEPE, de 11 de março de 2014. Estabelece normas sobre a política institucional de informação do Repositório de Informação Acessível (RIA) da Universidade Federal do Rio Grande do Norte (UFRN). Natal: UFRN.

Universidade Federal do Rio Grande do Norte [UFRN](2014b). Resolução n. 163/2014-CONSEPE, de 19 de agosto de 2014. Dispõe sobre a concessão de Bolsa Acessibilidade para Estudantes com Deficiência na Universidade Federal do Rio Grande do Norte. Natal: UFRN.

Universidade Federal do Rio Grande do Norte [UFRN] (2015). Número de estudantes ingressantes na UFRN no período de20112015. Arquivo de computador localizado no Banco de dados da Comissão Permanente de Apoio ao Estudante com Necessidades Educacionais Especiais. Natal. UFRN.

License information: This is an open-access article distributed under the terms of the Creative Commons Attribution License (type CCBY), which permits unrestricted use,distribution and reproduction in any medium, provided the original article is properly cited. 


\section{Sobre os autores}

Francisco Ricardo Lins Vieira de Melo (ricardolins67@gmail.com)

Pós-doutorado na Universidade do Algarve em Portugal (2015-2016). Doutorado (2006) e Mestrado (2002) em Educação pela UFRN, Graduação em Fisioterapia pela UFPB. Professor Associado, docente do Departamento de Fisioterapia, do Programa de Pós-Graduação em Educação da UFRN. Presidente da CAENE/UFRN desde 2010. Natal - RN. https://orcid.org/0000-0001-5902-9615

Eliana Rodrigues Araújo (eliana.ufrn@gmail.com)

Mestrado em Educação (2012) e Especialização em Psicopedagogia (2006) pela UFRN. Atuou como pedagoga da Comissão Permanente de Apoio a Estudantes com Necessidades Educacionais Especiais da Universidade Federal do Rio Grande do Norte - CAENE/UFRN. Natal - RN. https://orcid.org/0000-0001-9913-6722 